surfaces provide a simple means of immobilizing Co ions for enhanced electrocatalytic activity.

JEREMIAH T. ABIADE

\section{Suspended Carbon Nanotubes Display Negative Differential Conductance}

The conductance of single-walled carbon nanotubes (SWNTs) and other onedimensional nanomaterials is fundamentally important to a wide variety of electronic applications. It is well known that metallic SWNTs can carry tens of microamperes of current, achieving current densities two orders of magnitude higher than those possible with copper. Although it is generally true that the surrounding environment of such materials may substantially affect their electrical properties, only recently has a study been conducted on suspended SWNTs in native, unperturbed states. Researchers from the Department of Chemistry and Laboratory for Advanced Materials and the Department of Mechanical Engineering and Thermal Sciences at Stanford University have discovered that freely suspended metallic
SWNTs display electrical properties that are drastically different from those observed in SWNTs on substrates.

As reported in the October 7 issue of Physical Review Letters (\#155505; DOI: 10.1103/PhysRevLett.95.155505), researchers E. Pop, D. Mann, and J. Cao in Hongjie Dai's group at Stanford have found that the current-carrying ability of suspended SWNTs is reduced by up to an order of magnitude compared with SWNTs on substrates. In addition, the researchers found that suspended SWNTs display negative differential conductance at relatively low electric fields $(200 \mathrm{~V} / \mathrm{cm})$, that is, the current starts decreasing with applied bias beyond $\sim 0.2 \mathrm{~V}$ for $10-\mu \mathrm{m}$ long nanotubes. The researchers obtained suspended SWNTs with Pt electrical contacts by direct growth across pre-formed trenches 0.6-10 $\mu \mathrm{m}$ wide, and also, for comparison, fabricated similar SWNT devices lying on silicon nitride. The test article consisted of a silicon wafer with an oxide layer covered by a layer of silicon nitride and a series of Pt electrical contacts. The trenches were formed by removing the top silicon nitride layer and part of the oxide layer between some of the $\mathrm{Pt}$ contacts. The SWNTs grown on this test article spanned the silicon nitride in some regions and spanned trenches in other regions. Atomic force microscopy and scanning electron microscopy were used to characterize the devices. Current was measured as a function of voltage in vacuum at room temperature.

The researchers' theoretical analysis showed that the lack of a substrate allows significant self-heating in current-carrying suspended SWNTs. In addition, their unperturbed state enables a large population of nonequilibrium phonons with long lifetimes to build up, contributing to electron scattering and reduced current flow. By contrast, substrate-nanotube interactions aid both in heat dissipation and phonon relaxation, allowing higher currents, except, recent literature suggests, for nanotubes at biases greater than $1 \mathrm{~V}$, where self-heating and hot phonons are thought to exist.

"This," the researchers said, "raises the interesting possibility that SWNTs on substrates may be engineered to deliver higher currents than previously thought

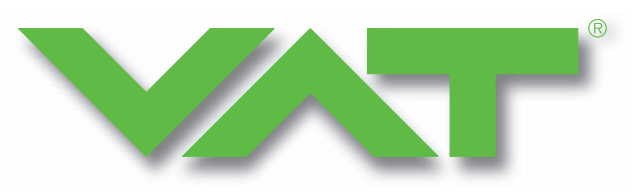

\section{Alumimum Vacuum Gate Valves DN 63, 80,100 Series $08.1 / 12.1$ for pump isolation and universal vacuum shut-off applications}

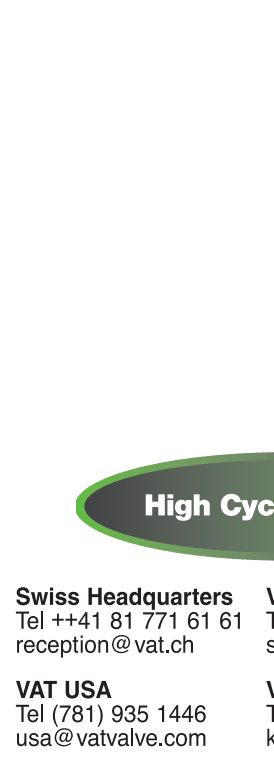

usa@vatvalve.com

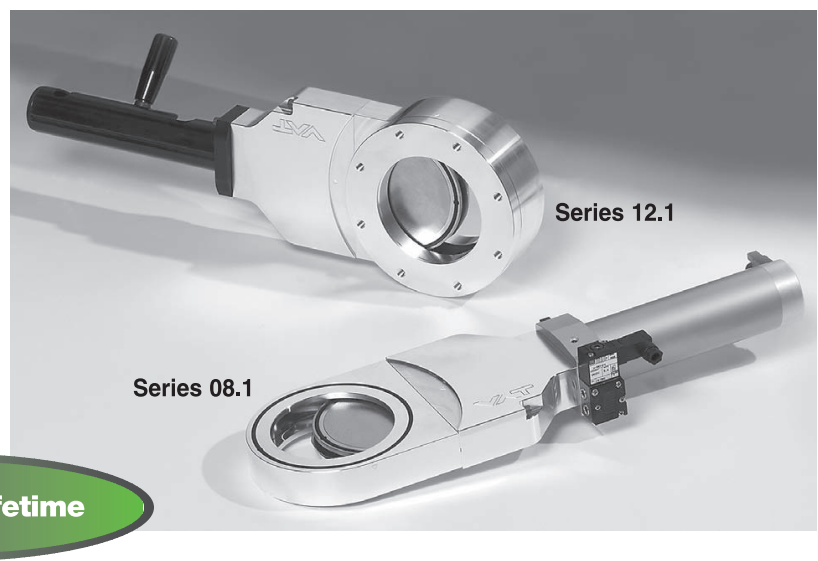

VAT Japan Tel (045) 3331144 sales@vatskk.co.jp VAT Korea $\begin{array}{ll}\text { Tel } 0317046857 & \text { Tel ++31(30) 6018251 } \\ \text { korea@vatvalve.com } & \text { benelux@vatvalve.com }\end{array}$

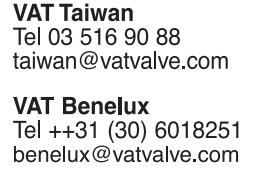

VAT France Tel 0169206911 france@vatvalve.com

VAT U.K. Tel 01926452753

VAT Germany
Tel (089) 465015

deutschland@vatvalve.com

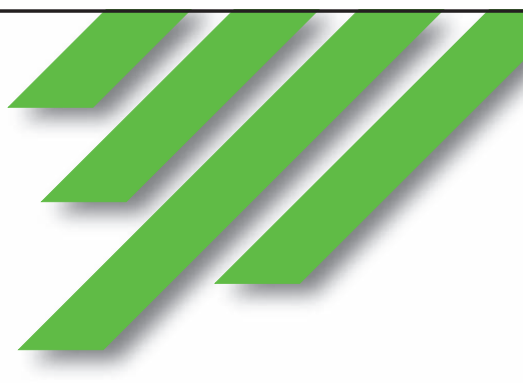

Low particle count and low shock

Quick and easy access for maintenance due to split body

Pneumatic, manual or electric actuation

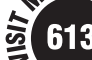

For more information, see http://advertisers.mrs.org 
possible (for a given tube length) through rational interface design for optimized heat dissipation and phonon relaxation." The discovery, they said, "may have general implications for high-current applications of quasi-1D materials." The researchers also said that their discovery may lead to new device applications consisting of suspended SWNTs.

STEVEN TROHALAKI

\section{Reversible Guest Exchange} Demonstrates Robustness of Zinc-Porphyrin-Based 3D Coordination Networks

Porous crystalline solids with a controlled pore size are attractive candidates for use in gas storage and separation, specific sorption, ion exchange, and catalysis. Three-dimensional porous crystalline materials are often assembled from precur-

\section{Cost-Effective Portable Spin Coater}

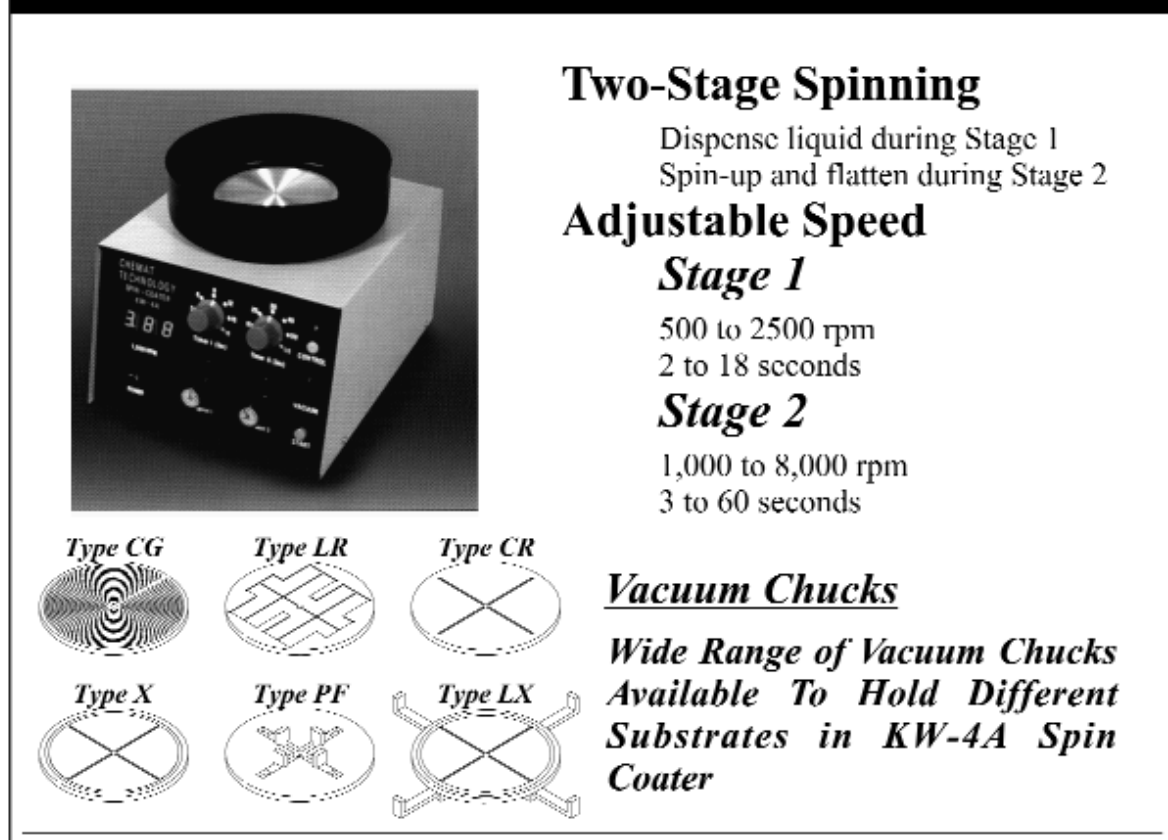

\section{KW-4A SERIES PRODUCT LINE}

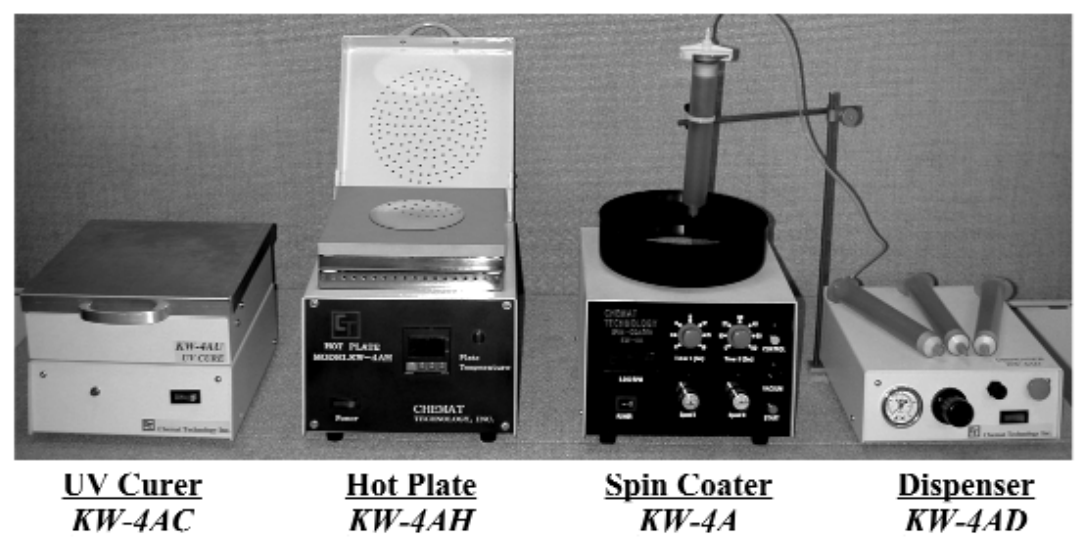

CHEMAT TECHNOIOGY, INC. 9036 Winnetka $\Lambda$ venue, Northridge, $\mathrm{C} \wedge \mathbf{\Lambda} 91324$ 1-800-475-3628, Fax: 818-727-9477 website: www.enlabproducts.com ; www.chemat.com email: marketing(a)chemat.com

For more information, see http://advertisers.mrs.org 